\title{
Case report 572
}

C. Brandon, M.D. ${ }^{1}$, W. Martel, M.D. ${ }^{1}$, L. Weatherbee, M.D. ${ }^{2}$, and P. Capek, M.D. ${ }^{1}$

Departments of ${ }^{1}$ Radiology and ${ }^{2}$ Pathology, University of Michigan Hospitals, Ann Arbor, Michigan, USA
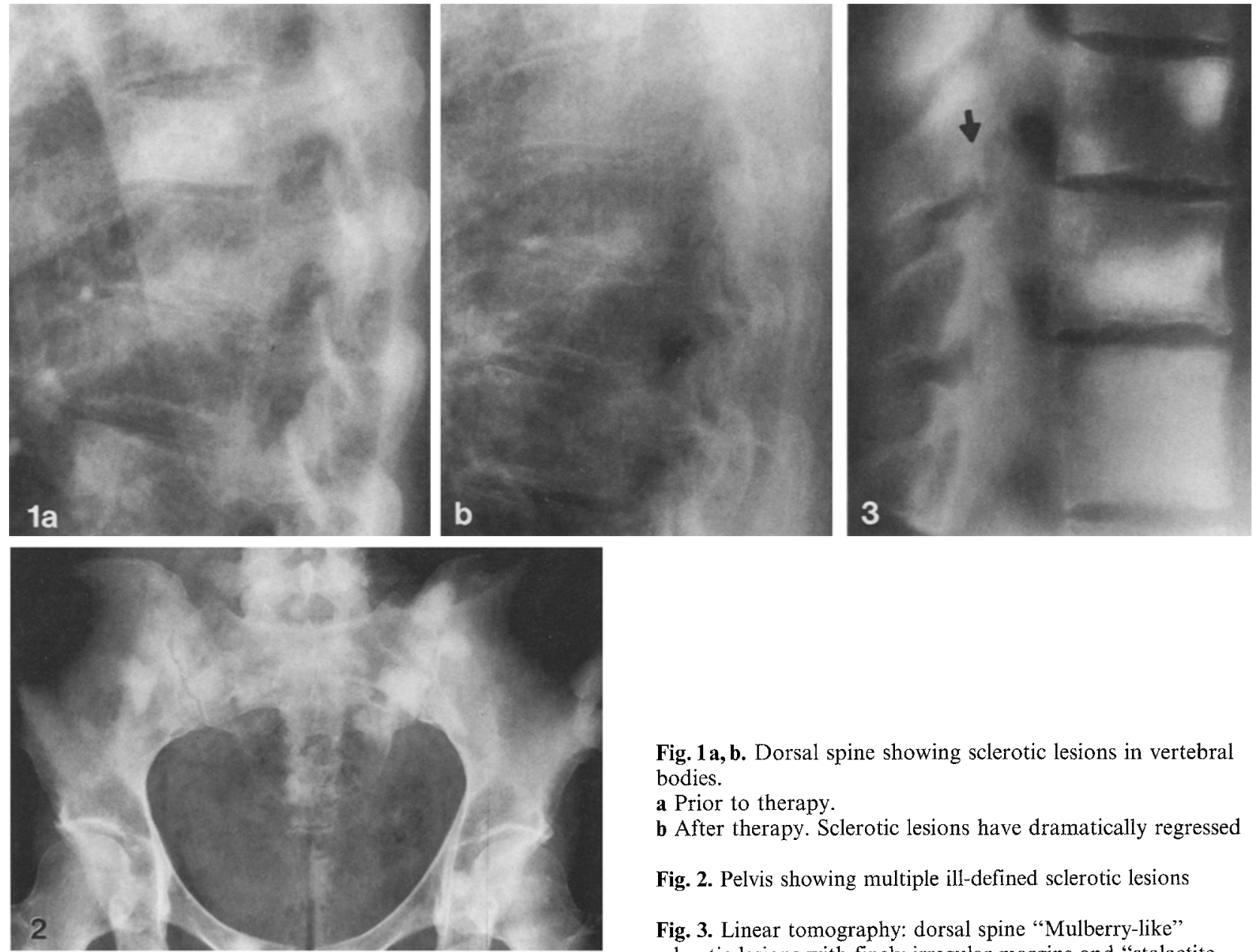

Fig. 1a,b. Dorsal spine showing sclerotic lesions in vertebral bodies.

a Prior to therapy.

b After therapy. Sclerotic lesions have dramatically regressed

Fig. 2. Pelvis showing multiple ill-defined sclerotic lesions

Fig. 3. Linear tomography: dorsal spine "Mulberry-like" sclerotic lesions with finely irregular margins and "stalactitelike" excrescences at margins of apophyses (arrow)

Address reprint requests to: William Martel, M. D., Department of Radiology; University of Michigan Hospitals, 1500 East Medical Center Drive, Ann Arbor, MI 48109-0300, USA 


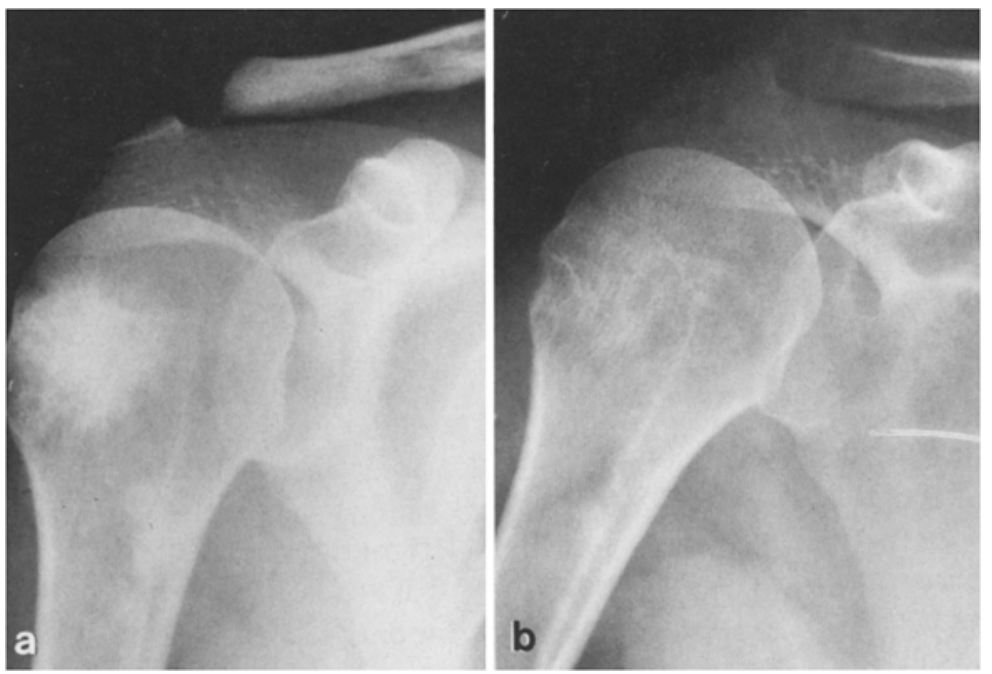

Fig. 4a, b. Right shoulder.

a Prior to therapy.

b After therapy. Sclerotic lesions in the distal end of the clavicle and the proximal end of the humerus, which regressed dramatically after therapy. Note lace-like irregularities in the periphery of the scelerotic lesions in the humerus

\section{Clinical information}

This forty-two-year-old woman presented with a three-year history of muscular weakness and numbness of her legs, accompanied by sharp pains and difficulty in walking. She had a 50-lb weight loss with frequent diarrhea for six months, dysmenorrhea for one year, and coarse skin with hirsutism. A previous evaluation had detected a polyneuropathy and multiple, focal osteosclerotic lesions in the lumbar spine, iliac crest, and sacrum.

On physical examination she was a thin, chronically ill appearing woman with increased hair on the face and extremities. She had marked muscular atrophy and weakness of facial and extremity musculature; the distal extremities were more severely affected. Her gait was wide-based and she had a mild distal tremor and slow alternating movements. Tendon reflexes were diminished with a distal gradient loss to pain and vibration sensation. She had moderate hepatomegaly and orthostatic cyanosis. Routine hematological and blood chemistries were normal except for elevated hemoglobin and hematocrit.
Protein electrophoresis of urine and serum was normal except for an elevated serum IgA. Cerebrospinal fluid analysis was normal. Rectal biopsy for amyloid, biopsy of a cervical lymph node for lymphoma and biopsies of bone marrow and liver were all normal.

On a radiological skeletal survey there were multiple osteosclerotic lesions in the ribs, vertebral bodies, (Fig. 1) clavicles, humeri, pelvic bones (Fig. 2) and proximal femora, which were poorly marginated. No lytic lesions were present. Linear tomography of the involved vertebrae (Fig. 3) showed irregular cortical excrescences, especially near the spinal apophyses which resembled stalagmites and stalactites. Some of the sclerotic lesions were quite dense but many had fine irregular margins which extended into the spongiosa. On plain films the humeral lesions had fine, lace-like irregularities at the peripheries (Fig. 4A). At this time a technetium radionuclide scan was negative.

A needle biopsy under fluoroscopic guidance of an osteosclerotic lesion in the head of the right humerus was performed. 


\section{Diagnosis: Osteosclerotic myeloma (POEMS syndrome)}

\section{Pathological features}

Insufficient bone was obtained to unequivocally assess the sclerosis, but the trabeculae were dense, irregular and thickened with focal appositional bone formation and irregular remodeling. Clusters of plasma cells were noted along the surface of the bone. The adjacent marrow contained increased plasma cells and in a few areas $80 \%$ or more of the marrow components were aggregates of plasma cells with moderate nuclear pleomorphism and occasional double nuclei (Fig. 5). A bone marrow biopsy of normal appearing ilium was normal. A diagnosis of myeloma was made on the basis of this humeral biopsy.

Twenty-two months of melphalan and prednisone chemotherapy resulted in complete resolution of pain, hirsutism and orthostatic cyanosis with marked improvement of her polyneuropathy and increased muscle strength in the distal extremities. Following chemotherapy the serum $\operatorname{IgA}$ returned to within normal limits and there was significant resolution of the osteosclerotic lesions with complete regression of some lesions (Figs. 1B and 4B). Currently the patient has minimal symptoms and no evidence of recurrent disease. A more detailed discussion of this patient's neurological course has been presented previously [5].

\section{Discussion}

Osteosclerotic lesions, even when mixed with lytic areas, are rare in myeloma, occurring in less than $3 \%$ of patients $[3,8,10,17]$. Whereas in osteolytic myeloma only $3 \%$ of patients have polyneuropathy [16], the incidence of polyneuropathy in osteosclerotic myeloma has been reported as $30-50 \%$ $[1,5,9,10,11,12]$. Patients with polyneuropathy and osteosclerotic lesions tend to be younger and more likely male than the usual myeloma patient and to have a different monoclonal protein and light chain composition $[6,9]$.

Many of the patients with polyneuropathy and osteosclerotic lesions have an unusual constellation of clinical and laboratory features which Takatsuki [18] first recognized as a clinical syndrome. Bardwick [2] in 1980 introduced the acronym "POEMS" to describe the cardinal features of polyneuropathy, organomegaly, endocrinopathy, $M$ protein and skin changes. Sensory and motor polyneuropathy is most characteristic and tends to be present before other features. Organomegaly includes hepatosplenomegaly and lymphadenopathy. Endocrine abnormalities may be reflected in amenorrhea, impotence, gynecomastia, diabetes, or hirsutism. POEMS patients tend to have a lower percentage of immunoglobulin abnormalities in serum and urine. $M$ protein $a b-$ normalities in POEMS, if present, are lambda light chains, unlike the kappa light chains for classical myeloma. These patients do not have an increased incidence of amyloidosis and rarely have Bence Jones proteinuria. Skin changes include hyperpigmentation, digital clubbing and hypertrichosis $[2,4,5,9,19]$. Not all of these features need to be present, but the association of sclerotic skeletal lesions is high $[2,6]$. Bone pain is rarely a component in POEMS presentations unlike classical myeloma.

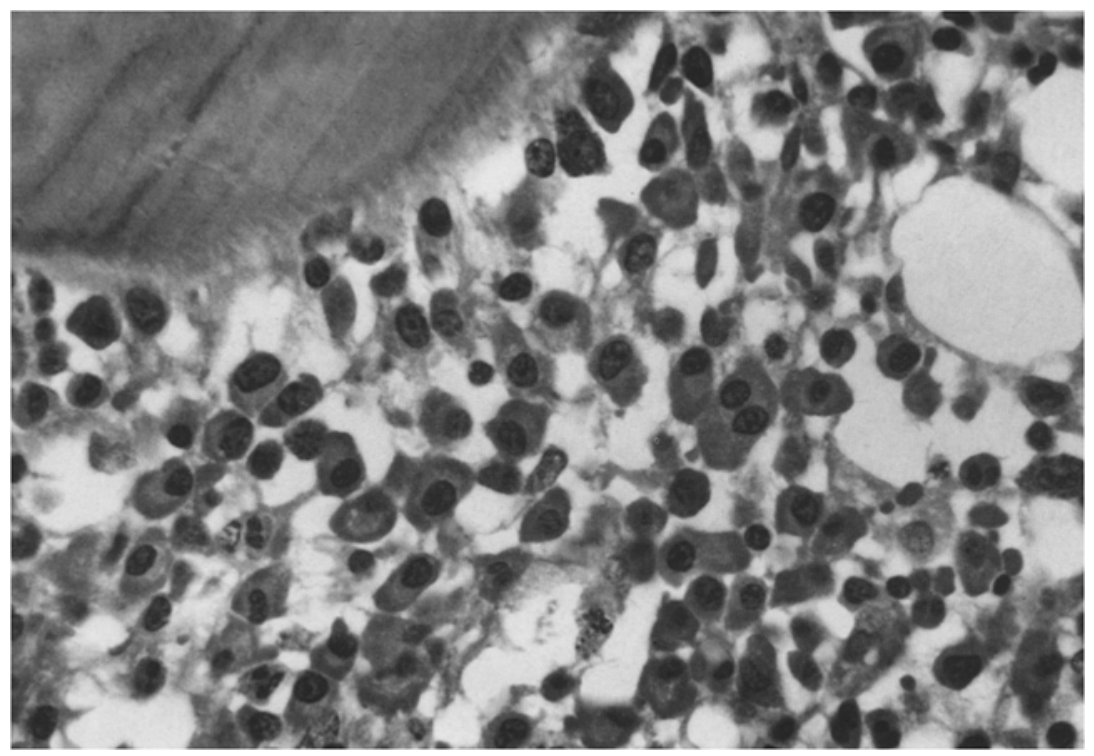

Fig. 5. A thickened bone trabecula is noted in the upper left corner. The marrow consists almost entirely of plasma cells which are moderately pleomorphic. Note the double nucleus in the cell at right center $(\mathrm{HE}, \times 250)$ 
Clinical improvement has followed both systemic chemotherapy and radiation of focal osseous lesions. Sometimes, as in our case, the diagnosis of plasma cell dyscrasia cannot be made on bone marrow biopsy and is evident only when the sclerotic lesions are biopsied $[1,2,10,13,14,15]$.

Certain radiological findings of osseous lesions in POEMS were emphasized by Resnick $[14,15]$. He described three cases with irregular spiculated, osseous proliferations involving multiple tendinous and ligamentous attachments, especially at the cortices of the posterior spinal elements. The current case showed similar findings, as well as multiple areas of osteosclerosis. These areas did not have lucent centers of bone destruction with a surrounding rim of sclerotic bone which has occasionally been described in sclerotic myeloma [3,4] and POEMS [8,14]. Sclerotic areas within the vertebral bodies ranged from very dense bone, resembling ivory vertebrae, to fine, sclerotic lesions with peripheral irregularities and spiculations within the spongiosa. The right humerus contained a lesion with such fine, sharp, spiculated contours extending away from the cortex into the spongiosa.

Of interest in our case, and not previously described to our knowledge, was the character of the lesions involving the spongiosa. The sclerosis often showed a lace-like or "mulberry", non-homogenous pattern with sharply defined, spiculated contours. These contours resemble the histological and radiographic appearance of bone islands with focal condensations of compact lamellar bone within the spongiosa. The sharpness of the sclerotic spiculations, whether in cortex or spongiosa, may reflect the relative inactivity of the osteoblastic process at these sites. This is supported by the negative bone scan in our case. It is of interest that bone scans are negative in the majority of cases with bone islands [7]. Furthermore, the spiculated contours of spongiosa may have the same pathological basis as the "stalagmite/stalactite" appearance of the vertebral cortical excrescences.

Patients with POEMS syndrome can have marked amelioration of their clinical and laboratory findings after combination of chemotherapy and radiation, but the radiographic appearance is usually unchanged $[2,4,8,13]$. This case report and possibly two other cases of POEMS-like osteosclerotic myeloma described by Reitan [13] had reduction of osteosclerotic foci following chemotherapy. Reitan's first case was also treated with melphalan and prednisone but with only slight improvement of neurological symptoms. However, the number of multiple osteosclerotic foci throughout the skeleton underwent considerable reduction after almost 10 years of treatment. In the second case, after receiving a different chemotherapeutic regime, there was progression of neurological symptoms and most of the bone lesions, with the exception of several skull lesions, disappeared.

Of interest is a reported case of POEMS syndrome in giant lymph node hyperplasia in which there were osteoblastic lesions [4]. We recently observed a case with giant lymph node hyperplasia and osteoblastic lesions. In this case there were no manifestations of POEMS syndrome and the plasma cell infiltrates on autopsy were benign in appearance.

\section{References}

1. Aguayo A, Thompson DW, Humphrey JG (1964) Multiple myeloma with polyneuropathy and osteosclerotic lesions. J Neurol Neurosurg Psychiat 27:562

2. Bardwick PA, Zvaifler NJ, Gill GN, Newman D, Greenway GD, Resnick DL (1981) Plasma cell dyscrasia with polyneuropathy, organomegaly, endocrinopathy, M-Protein, and skin changes: The POEMS syndrome. Report on two cases and a review of the literature. Medicine 59:4:311

3. Bismuth V, Dreyfus B, Chomette G, Vaugier G, Sultan C, Escourolle R, Blery M (1971) Myelomes multiples avec osteocondensation diffuse: a propos de deux cas. Ann Radio 14: 769

4. Bitter MA, Komaiko W, Franklin WA (1985) Giant lymph node hyperplasia with osteoblastic bone lesions and the POEMS (Takatsuki's) syndrome. Cancer 56:188

5. Donofrio PD, Albers JW, Greenberg HS, Mitchell BS (1984) Peripheral neuropathy in osteosclerotic myeloma: clinical and electrodiagnostic improvement with chemotherapy. Muscle Nerve 7:137

6. Driedger H, Pruzanski W (1979) Plasma cell neoplasia with osteosclerotic lesions: a study of five cases and a review of the literature. Arch Intern Med 139:892

7. Hall FM, Goldberg RP, Davies JAK, Fainsinger MH (1960) Scintigraphic assessment of bone islands. Radiology 135:737

8. Hall FM, Gore SM (1988) Osteosclerotic myeloma variants. Skeletal Radiol 17:101

9. Iwashita H, Ohnishi A, Asada M, Kanazawa Y, Kuroiwa Y (1977) Polyneuropathy, skin hyperpigmentation, edema, and hypertrichosis in localized osteosclerotic myeloma. Neurology 27:675

10. Kelly JJ, Kyle RA, Miles JM, Dyck PJ (1983) Osteosclerotic myeloma and peripheral neuropathy. Neurology 33:202

11. Morley JB, Schwieger AC (1967) The relation between chronic polyneuropathy and osteosclerotic myeloma. J Neurol Neurosurg Psychiat 30: 432

12. Ohi T, Kyle RA, Dyck PJ (1985) Axonal attenuation and secondary degmental demyelination in myeloma neuropathies. Ann Neurol 17:3:233

13. Reitan JB, Pape E, Fossa S, Julsrud O, Slettnes ON, Sholheim OP (1980) Osteosclerotic myeloma with polyneuropathy. Acta Med Scand 208:137

14. Resnick D, Greenway GD, Bardwick PA, Zvaifler NJ, Gill GN, Newman DR (1981) Plasma-cell dyscrasia with polyneuropathy, organomegaly, endocrinopathy, M-Protein, and 
skin changes: the POEMS syndrome. Distinetive radiographic abnormalities. Radiology 140:17

15. Resnick D, Haghighi P, Guerra J (1984) Bone sclerosis and proliferation in a man with multisystem disease. Invest Radiol 19:1

16. Rousseau JJ, Franck G, Grisar T, Reznik M, Heynen G, Salmon I (1978) Osteosclerotic myeloma with polyneuropathy and ectopic secretion of calcitonin. Europ J Cancer 14:133
17. Skin YS, Mowry RW, Bodie FL (1979) Osteosclerosis (punctate form) in multiple myeloma. South Med J 171:226

18. Takatsuki K, Uchiyama T, Sagawa K, Yodoi J (1976) Plasma cell dyscrasia with polyneuropathy and endocrine disorders: review of 32 cases. Int Congr Hemat (Kyoto) Excerpta Medica 415:454

19. Tanaka O, Ohsawa T (1984) The POEMS syndrome: report of three cases with radiographic abnormalities. Radiologe $24: 472$ 